Vol 11, Issue 9, 2018

\title{
ENHANCEMENT OF SOLUBILITY AND OPTIMIZATION OF ORALLY DISINTEGRATING FILMS OF ACYCLOVIR
}

\author{
BIKASH PANDEY, ARSHAD BASHIR KHAN* \\ Department of Pharmaceutics, Krupanidhi College of Pharmacy, Carmelaram, Varthur Hobli, Bengaluru - 560 035, Karnataka, India. \\ Email: arshad.krupanidhi@gmail.com
}

Received: 25 April 2018, Revised and Accepted: 26 May 2018

\begin{abstract}
Objective: The objective of this work was to prepare and optimize orally disintegrating films of acyclovir (ACV), which is a known antiviral agent. To enhance the solubility of ACV, solid dispersions of ACV were made.

Methods: The films were prepared using a solvent casting technique. Full factorial design was utilized for the optimization of the effect of independent variables such as the amount of hydroxypropyl methylcellulose $5 \mathrm{cps}$, sodium starch glycolate, and propylene glycol on the disintegration time. Other evaluation tests such as drug release, drug content, thickness, and folding endurance of film were also conducted.

Results: Compatibility studies by Fourier transform infrared showed that there was no significant interaction between the drug and excipients used. Disintegration time was found to be $43 \mathrm{~s}$ for the optimized batch. The in vitro release profile of formulation response disintegrating time in phosphate buffer pH 6.8 revealed that there was a significant increment in drug release of the optimized batch in comparison to the screening batches. Further, short-term accelerated stability studies carried out for 4 weeks for the optimized formulation which proved that the formulated films were stable at the accelerated conditions of temperature and humidity $\left(40 \pm 2^{\circ} \mathrm{C} / 75 \pm 5 \% \mathrm{RH}\right)$.
\end{abstract}

Conclusions: It was concluded that such ACV solid dispersion films could be beneficial in enhancement of dissolution and consequently the oral bioavailability of ACV.

Keywords: Acyclovir, Factorial design, Oral disintegrating films, Solid dispersion, Solubility enhancement.

(C) 2018 The Authors. Published by Innovare Academic Sciences Pvt Ltd. This is an open access article under the CC BY license (http://creativecommons. org/licenses/by/4. 0/) DOI: http://dx.doi.org/10.22159/ajpcr.2018.v11i9.26891

\section{INTRODUCTION}

In recent times, there has been an augmented requirement for patientcompliant dosage forms. Consequently, the demand for innovative and patient-friendly dosage forms is forecasted to be the whopping US $\$ 15,984.3$ billion by the end of 2024 up from the US $\$ 7,337.8$ million in 2015 [1]. Fast-dissolving dosage forms were initiated in the past century in the seventies as a substitute to tablets, capsules, and syrups for pediatric and geriatric patients who have trouble swallowing conventional oral solid-dosage forms. The popularity of oral dosage forms is evidently because of the patient compliance, ease in administration, and accurate dosing, price, and superior longevity in terms of stability. Oral films are one such patient-friendly dosage forms. Fast or rapidly disintegrating film is conveniently placed on the tongue where it disintegrates. If it is required, the formulation can be designed to quickly disintegrate releasing the medication without delay. This would present the drug in a liberated form to the gastrointestinal tract where the absorption is quickened. Oral dissolving films have the added benefit of not needing a glass of water for administration [2]. Orodispersible films have been successfully formulated and evaluated for drugs such as metoclopramide [3]. Different polymers have been used for making oral films such as hydroxypropyl methylcellulose (HPMC) and sodium carboxymethylcellulose [4].

Acyclovir (ACV) is an antiviral agent, which is indicated chiefly for the treatment of infection arising due to herpes simplex virus, chickenpox, and shingles. ACV is known by its IUPAC name as 2-amino-1,9-dihydro9-[(2-hydroxyethoxy)methyl]-6H-purin-6-one [3]. Its half-life is reported to be $2-4 \mathrm{~h}$ and protein binding to be $9-33 \%$. Water solubility is poor at $2.5 \mathrm{mg} / \mathrm{ml}$. In humans, the average oral bioavailability of ACV after administration of a $200 \mathrm{mg}$ dose is approximately $20 \%$, and this decreases to about $10 \%$ with $800 \mathrm{mg}$ dosing [5]. Due to its this low oral bioavailability, achievement of plasma concentration sufficient for inhibition of the less sensitive herpes simplex virus is not easy and intravenous administration may be obligated for better efficacy. Solubility enhancement has been positively linked to increased oral absorption [5]; hence, in the present research, an attempt has been made to improve the solubility of ACV by making ACV solid dispersions (ACV-SDs) and formulating ACV-SD into oral films.

\section{MATERIALS AND METHODS}

Materials

ACV was a gift sample from Atul Limited, Gujarat, India, mannitol purchased from Loba Chemie, Mumbai, India, dimethyl sulfoxide (DMSO), polyvinylpyrrolidone K 30, glycerol purchased from Thermo Fisher Scientific, Bangalore, India, HPMC 5 cps HPMC K15, ethanol, sodium starch glycolate (SSG), propylene glycol, sodium hydroxide, and potassium dihydrogen phosphate purchased from SD Fine-Chem Ltd., Mumbai, India.

\section{Equipment}

Bath sonicator - Sidilu renewable energy, Bangalore, India; Digital balance - Ohaus, India; pH meter - Analytical technologies Ltd., Gujarat, India; UV Visible spectrophotometer - Shimadzu, Corporation, Japan; Disintegration apparatus -Electrolab, Mumbai, India; 8-station dissolution apparatus, LabIndia disso 8000, India; Fourier transforminfrared (FTIR) spectrometer - Bruker, USA; Hot air oven - Techno scientific, Bangalore, India.

\section{Methodology}

Preformulation studies

Solubility of ACV

The solubility of ACV was checked in ethanol, DMSO, water, phosphate buffer solution (PBS), and $\mathrm{pH} 6.8$ using the shake-flask technique 
Table 1: Preliminary trial batches for preparing of blank films

\begin{tabular}{|c|c|c|c|c|c|c|c|c|c|}
\hline \multirow[t]{2}{*}{ S. No. } & \multirow[t]{2}{*}{ Ingredients } & \multicolumn{8}{|c|}{ Batches } \\
\hline & & T1 & T2 & T3 & T4 & T5 & T6 & & T7 \\
\hline 1 & HPMC K15 (mg) & 250 & & & & & & & \\
\hline 3 & HPMC 100 (mg) & & & 250 & & & & & \\
\hline 4 & HPMC 5 cps (mg) & & & & 250 & & & & \\
\hline 5 & HPMC E (mg) & & & & & 250 & & & \\
\hline 6 & PVP K 30 (mg) & & & & & & 250 & & \\
\hline 7 & HPMC 5 cps: HPMC K15 (mg) & & & & & & & & $250: 250$ \\
\hline 8 & Glycerol (mg) & 200 & 200 & 200 & 200 & 200 & 200 & & 200 \\
\hline 9 & Vehicle q.s $10 \mathrm{ml}$ & Water & Water & Water & Water & Water & Water & Water & \\
\hline
\end{tabular}

HPMC: Hydroxypropyl methylcellulose, PVP: Polyvinylpyrrolidone

[6]. Briefly, an excess amount of ACV was added to $5 \mathrm{ml}$ of each of the above liquids and shake for $48 \mathrm{~h}$ to achieve equilibrium, then filtered through Whatman filter paper \#1 and analyzed spectrophotometrically at $\lambda_{\max } 252 \mathrm{~nm}$.

\section{Compatibility studies}

The FTIR spectrum of ACV was generated using the potassium pellet method. A little quantity of the drugs ACV was intimately mixed with potassium bromide (preheated at $105^{\circ}$ for $1 \mathrm{~h}$ in an oven). Then, the mixture was made into a disc using a press machine. The disc was then analyzed to generate the FTIR. Similarly, ACV-excipient mixture was also studied.

Preparation of solid dispersion

The carrier used was mannitol. Solid dispersion was prepared by coevaporation of equimolar ACV - mannitol in dimethyl sulfoxide solution on the water bath $70-90^{\circ} \mathrm{C}$. Each solid product after complete evaporation of solvent used was then scrapped off, pulverized, and sieved through $80 \#$. The preliminary trial batch is shown in Table 1.

\section{Formulation of blank mouth dissolving films}

Formulation trial T4 showed good film-forming properties than other formulation; hence, HPMC 5 cps was selected for further film formulation.

\section{Formulation of fast disintegrating film of ACV-SD}

Weighed amount of film-forming polymer was added to water and stirred at a rotation of 100-120 rpm using magnetic stirrer. ACV-SD containing equivalent amount of drug $(200 \mathrm{mg})$ was then added into the solution with magnetic stirring for 2-3 min at rotation speed of 150$200 \mathrm{rpm}$. Other excipients such as plasticizer and superdisintegrant were then added one by one with continuous stirring. The solution mixture was then slowly poured into a Petri plate, and solvent was allowed to evaporate at a temperature of $60^{\circ} \mathrm{C}$ using hot air oven overnight. After solvent was evaporated completely, the strip was slowly peeled.

\section{Formulation of screening batch}

To identify the vital factors affecting the desired response, a screening design was followed. The screening batches were formulated based on the definitive screening design done with the help of statistical software JMP ${ }^{\circledR} 11$ by SAS for three factors - the amounts of HPMC (5 cps), SSG, and glycerol (plasticizer). The design was performed for eight experimental runs with the amounts of HPMC 5 cps and SSG ranging from 250 to $500 \mathrm{mg}$ and 5 to $20 \mathrm{mg}$, respectively. These ranges were decided based on a prior literature survey. Evaluations of these batches were performed the screening batches are shown in Table 2 .

Based on the result of screening batches, an optimized formulation (Table 3) was designed and evaluated for disintegration time.
Table 2: Screening batches of ACV-SD

\begin{tabular}{|c|c|c|c|c|c|}
\hline \multirow[t]{2}{*}{ S. No. } & \multirow{2}{*}{$\begin{array}{l}\text { ACV-SD } \\
\text { (mg) }\end{array}$} & \multirow{2}{*}{$\begin{array}{l}\text { HPMC } 5 \text { cps } \\
\text { (mg) }\end{array}$} & Plasticizer & \multirow{2}{*}{$\begin{array}{l}\text { SSG } \\
\text { (mg) }\end{array}$} & \multirow{2}{*}{$\begin{array}{l}\text { Water } \\
(\mathrm{ml})\end{array}$} \\
\hline & & & Glycerol (ml) & & \\
\hline $\mathrm{F} 1$ & 200 & 250 & 0.25 & 20 & 10 \\
\hline $\mathrm{F} 2$ & 200 & 500 & 0.25 & 20 & 10 \\
\hline F3 & 200 & 500 & 0.25 & 5 & 10 \\
\hline F4 & 200 & 250 & 0.5 & 20 & 10 \\
\hline F5 & 200 & 250 & 0.25 & 5 & 10 \\
\hline F6 & 200 & 250 & 0.5 & 5 & 10 \\
\hline F7 & 200 & 500 & 0.5 & 5 & 10 \\
\hline F8 & 200 & 500 & 0.5 & 20 & 10 \\
\hline
\end{tabular}

HPMC: Hydroxypropyl methylcellulose, ACV-SD: Acyclovir solid dispersion, SSG: Sodium starch glycolate

Table 3: Optimized formula

\begin{tabular}{lll}
\hline S. No. & Factor & Amount \\
\hline 1 & HPMC 5 cps (mg) & 375 \\
2 & SSG (mg) & 11.912 \\
3 & Glycerol (ml) & 0.375 \\
\hline
\end{tabular}

HPMC: Hydroxypropyl methylcellulose, SSG: Sodium starch glycolate

Table 4: Solubility studies of acyclovir and solid dispersion

\begin{tabular}{lll}
\hline S. No. & Solvent & Solubility $(\mathbf{m g} / \mathbf{m l})$ \\
\hline 1 & Ethanol-SD & 2.447 \\
2 & DMSO-SD & 45.54 \\
3 & Water-SD & 4.74 \\
4 & pH 6.8-SD & 29.64 \\
5 & Ethanol-PD & 5.69 \\
6 & DMSO-PD & 40.41 \\
7 & Water-PD & 24.93 \\
8 & pH 6.8-PD & 0.355 \\
\hline
\end{tabular}

DMSO: Dimethyl sulfoxide

\section{Evaluation studies of orally disintegrating films of ACV}

Thickness

The thickness of films was measured using screw gauge at three different points of the film and an average was taken.

Drug content

$2.5 \mathrm{~cm}^{2}$ containing $2.5 \mathrm{mg}$ of ACV was cut evenly and grinded. It was then added to $100 \mathrm{ml}$ volumetric flask and diluted using PBS pH 6.8. It was then sonicated for 15-20 min. A further dilution was made to Beer's range and the absorbance was measured using UV spectrophotometer at $252 \mathrm{~nm} \lambda_{\max }$.

Folding endurance

Area of films $(4.5 \mathrm{~cm} \times 2.5 \mathrm{~cm})$ was cut evenly and repeatedly folded at the same place till it broke. The number of times the films could be 
folded the same place without breaking gave the exact value of folding endurance.

Disintegration time

A small strip of film is placed in beaker containing $15 \mathrm{ml}$ of phosphate buffer $\mathrm{pH} 6.8$ and continuously shaken until the strip disintegrates completely.

\section{Surface $p H$}

Surface $\mathrm{pH}$ of film was determined by placing the film on the surface of $1.5 \%$ agar gel followed by placing $\mathrm{pH}$ paper ( $\mathrm{pH}$ range 1-11) on the films. The change in the color of $\mathrm{pH}$ paper was observed.

In vitro release studies

An area of film containing equivalent amount of ACV $(2.5 \mathrm{mg}) \mathrm{cm}^{2}$ was weighted and added to $900 \mathrm{ml}$ of phosphate buffer pH 6.8 (USP-II dissolution apparatus) at $37^{\circ} \mathrm{C}$ using at a rotation speed of $50 \mathrm{rpm}$. $5 \mathrm{ml}$ sample was withdrawn at an interval of 5, 15, 30, 45, and $60 \mathrm{~min}$. An equal amount of fresh dissolution medium was added back, respectively, at each time interval after withdrawal of the test sample. Test sample was filtered through Whatman filter paper no 1 and suitably diluted. The absorbance of the diluted sample was estimated for amounted of ACV dissolved by measuring in UV spectrophotometer at $252 \mathrm{~nm} \lambda_{\max }$

Drug-excipients interaction studies

FTIR spectroscopy

An FTIR spectrum was used to identify if any interaction existed between ACV and excipients used. Sample was analyzed by potassium bromide pellet method in an IR spectrophotometer (Bruker) in the region between 4000 and $400 / \mathrm{cm}$.

Table 5: Evaluation of screening batches

\begin{tabular}{|c|c|c|c|c|c|}
\hline S. No. & Code & Thickness $(\mu \mathrm{m}) \pm$ SD $(n=3)$ & Folding endurance $\pm S D(n+3)$ & Surface $p H \pm S D(n=3)$ & Disintegration time $(S) \pm S D(n=3)$ \\
\hline 1 & F1 & $85.66 \pm 3.055$ & $84.66 \pm 3.68$ & $7.073 \pm 0.030$ & $44.33 \pm 3.299$ \\
\hline 2 & $\mathrm{~F} 2$ & $65.66 \pm 2.081$ & $85 \pm 3.55$ & $7.4 \pm 0.1632$ & $40.33 \pm 2.054$ \\
\hline 3 & F3 & $86.33 \pm 2.081$ & $90 \pm 4.08$ & $7.33 \pm 0.049$ & $49.33 \pm 1.699$ \\
\hline 4 & $\mathrm{~F} 4$ & $95 \pm 2$ & $100 \pm 4.082$ & $7.46 \pm 0368$ & $37.66 \pm 2.054$ \\
\hline 5 & F5 & $80 \pm 2$ & $93 \pm 2.160$ & $7.25 \pm 0.142$ & $42.66 \pm 2.054$ \\
\hline 6 & F6 & $90.33 \pm 2.51$ & $83 \pm 2.160$ & $7.46 \pm 0.169$ & $50.33 \pm 1.699$ \\
\hline 7 & F7 & $86.66 \pm 1.527$ & $92.33 \pm 2.35$ & $7.33 \pm 0.265$ & $42.33 \pm 2.494$ \\
\hline
\end{tabular}

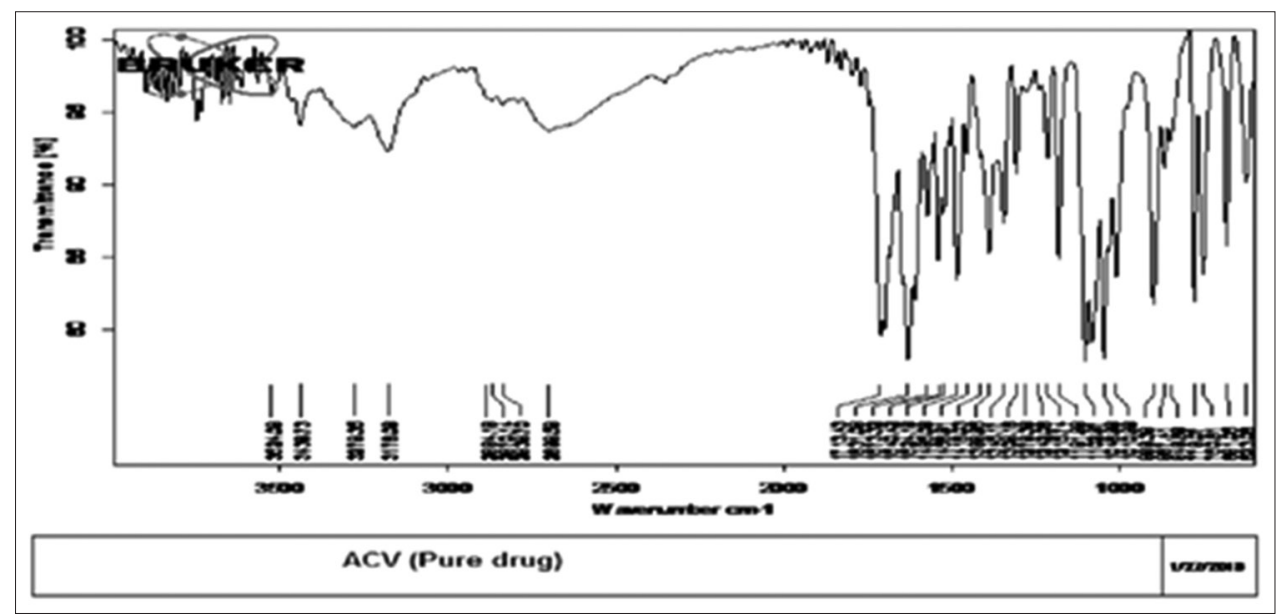

Fig. 1: Fourier transform-infrared spectrum of acyclovir (pure drug) after compatibility study

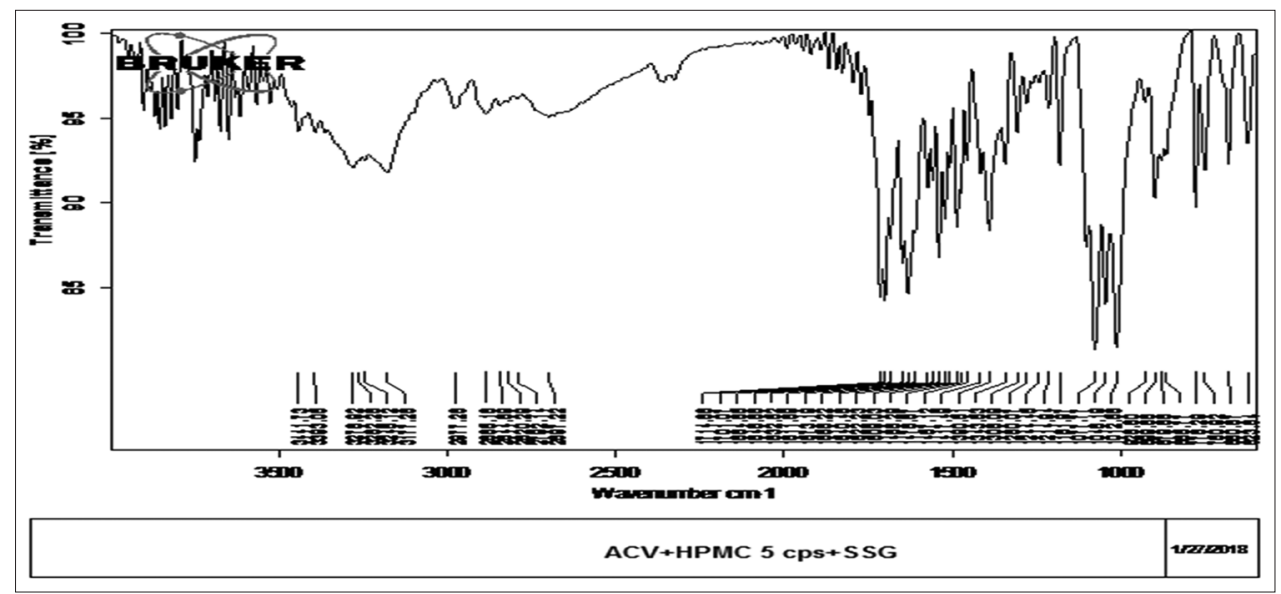

Fig. 2: Fourier transform-infrared spectrum of acyclovir-excipients after compatibility study 
Short-term accelerated stability studies

Stability studies accelerated were carried out for the optimized formulation which was kept at $40^{\circ} \mathrm{C} \pm 2^{\circ} \mathrm{C} / 75 \% \mathrm{RH}$ for 1 month. The percentage drug release and drug content were calculated at the end of 30 days, and FTIR was also recorded.

\section{RESULTS}

Table 4 summarizes the data for the solubility studies of ACV-SD. Figs. 1 and 2 present FTIR spectra for the compatibility study.

Table 5 summarizes the results of the screening batches. Fig. 3 and Table 6 present the results of the optimized formulation.

\section{Statistical analysis}

Tables 6-16 and Figs. 4-10 deal with the results of optimization.

\section{Optimization}

$\mathrm{Y}=$ Response disintegration time $(\mathrm{s})$

Singularity details: Intercept $=0.005 \times \operatorname{Drug}(\mathrm{mg})=0.1 \times$ Solvent $(\mathrm{ml})$

The comparative in vitro release profile before and after short-term accelerated stability study is presented in Fig. 11, while the FTIR of the optimized formulation is shown in Fig. 12.

Table 6: Summary of fit

\begin{tabular}{ll}
\hline $\mathrm{R}^{2}$ & 0.147204 \\
$\mathrm{R}^{2}$ Adj & -0.49239 \\
Root mean square error & 6.357258 \\
Mean of response & 44.9125 \\
Observations (or sum wgts.) & 8 \\
\hline
\end{tabular}

Table 7: Analysis of variance

\begin{tabular}{lllll}
\hline Source & DF & Sum of squares & Mean square & F ratio \\
\hline Model & 3 & 27.90445 & 9.3015 & 0.2302 \\
Error & 4 & 161.65890 & 40.4147 & Prob $>$ F \\
C. Total & 7 & 189.56335 & & 0.8713 \\
\hline
\end{tabular}

\section{DISCUSSION}

Pure drug had poor solubility of $0.35 \mathrm{mg} / \mathrm{ml}$ in PBS $\mathrm{pH} 6.8$; whereas, PD-SD has significantly improved solubility of $29.64 \mathrm{mg} / \mathrm{ml}$ in PBS $\mathrm{pH}$ 6.8. This may be due to the effect of the carrier mannitol which was can be explained by configuration of areas containing elevated levels of dissolved mannitol at the surface of drug crystals in which the drug may be solubilized $[7,8]$. Hence, it will advance the consequent diffusion of ACV followed by dilution in the mass of the solution. As

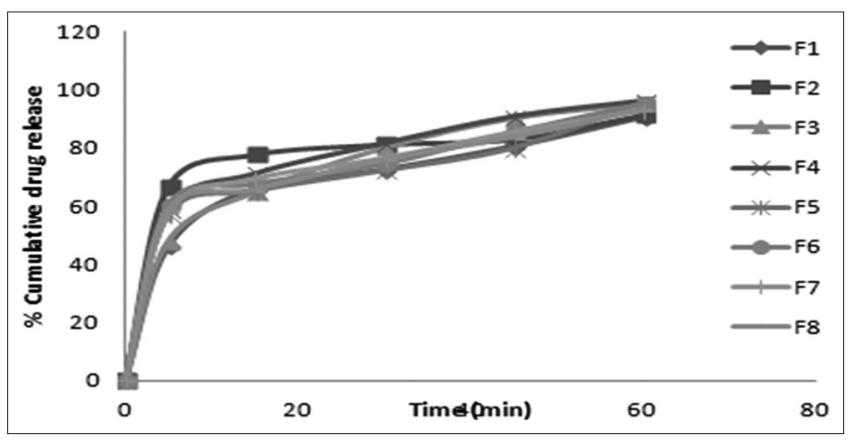

Fig. 3: In vitro release studies

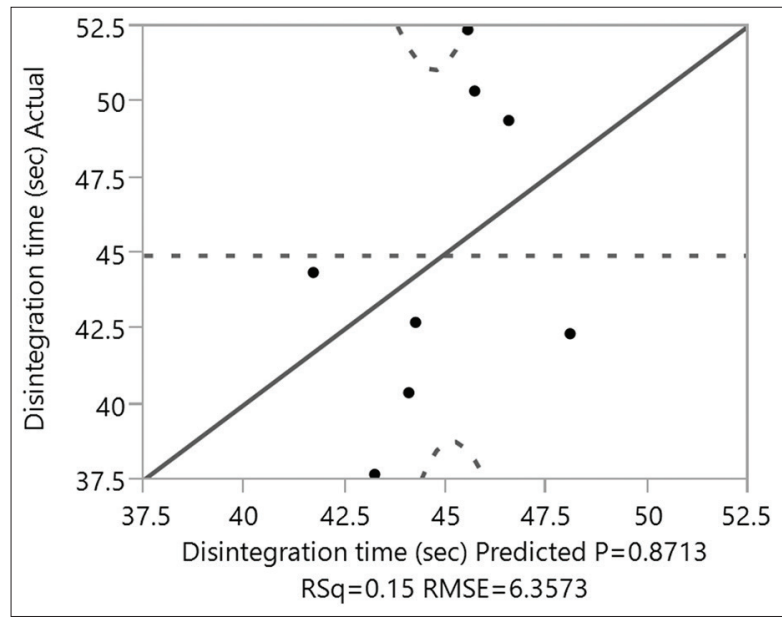

Fig. 4: Actual by predicted plot

Table 8: Parameter estimates

\begin{tabular}{lllll}
\hline Term & Type & Estimate & Standard error & t ratio \\
\hline Intercept & Biased & 41.243333 & 10.48894 & 3.93 \\
Drug (mg) & Zeroed & 0 & 0 & $0.0171^{*}$ \\
HPMC 5 (mg) & & 0.00934 & 0.017981 & 0.52 \\
Glycerol (ml) & & 6 & 17.98104 & 0.6309 \\
SSG (mg) & & -0.166667 & 0.299684 & 0.7554 \\
Solvent (ml) & Zeroed & 0 & 0 & 0.6078 \\
\hline
\end{tabular}

HPMC: Hydroxypropyl methylcellulose, SSG: Sodium starch glycolate

Table 9: Sorted parameter estimates

\begin{tabular}{|c|c|c|c|c|c|c|}
\hline Term & Type & Estimate & Standard error & t ratio & t ratio & $p>|t|$ \\
\hline SSG (mg) & & -0.166667 & 0.299684 & -0.56 & $\vdots:$ & 0.6078 \\
\hline HPMC 5 (mg) & & 0.00934 & 0.017981 & 0.52 & $\vdots: \vdots$ & 0.6309 \\
\hline Glycerol (ml) & & 6 & 17.98104 & 0.33 & $: \quad: \quad:$ & 0.7554 \\
\hline Drug (mg) & Zeroed & 0 & 0 & & | $: \quad: \quad: \quad: \quad: \quad: \quad: \quad:$ & \\
\hline
\end{tabular}

HPMC: Hydroxypropyl methylcellulose, SSG: Sodium starch glycolate 


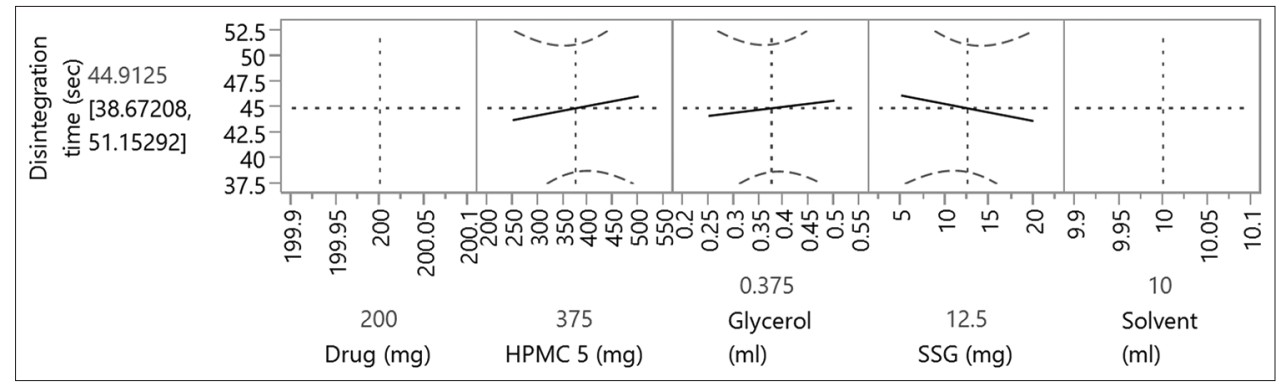

Fig. 5: Prediction profiler

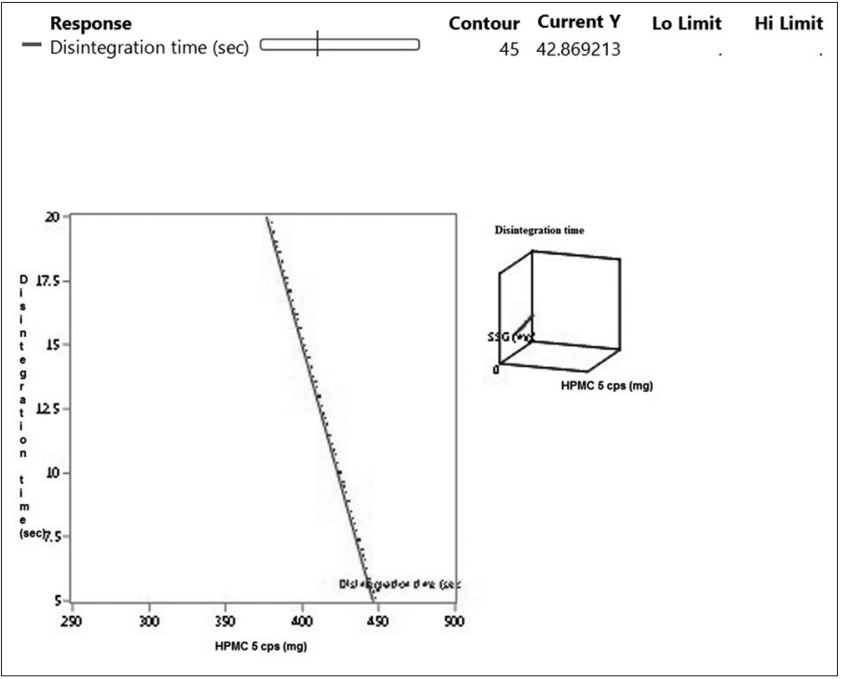

Fig. 6: Contour profiler

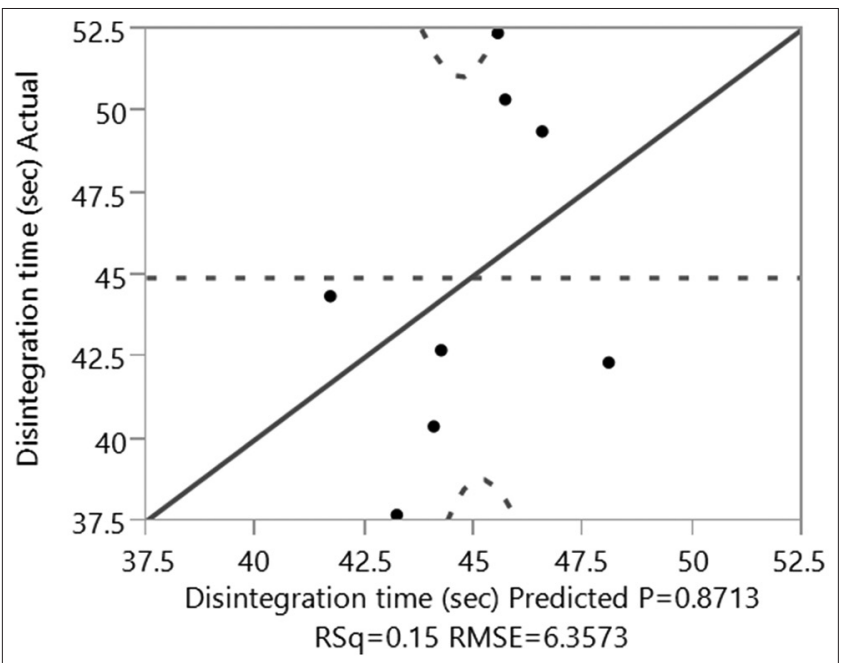

Fig. 7: Whole model actual by predicted plot

peaks of ACV were evident in the FTIR of mixture of ACV and other excipients, it proved that ACV was compatibility with the excipients. FTIR of pure drug ACV showed its characteristic major peaks $\left(\mathrm{cm}^{-1}\right)$ at 3524:OH stretching; 3439: $\mathrm{NH}_{2}$ stretching; 3278:C-H aliphatic stretching; 1713:C=O stretching; and 778: $\mathrm{C}=\mathrm{H}$ rocking. The FTIR spectra for drug-excipient compatibility study revealed no interaction between ACV and excipient (HPMC-5 and SSG) as evident by the main bands $\left(\mathrm{cm}^{-1}\right)$ of ACV at 3524:0-H overlapping; 3439: $\mathrm{NH}_{2}$ stretching; 3278: $\mathrm{C}-\mathrm{H}$ aliphatic stretching; $1713: \mathrm{C}=\mathrm{O}$ stretching; and 778:C=H rocking. Drug content for screening batches prepared was to be found lowest for F1 $(87 \% \pm 0.0084)$ and highest for F4 $(95 \% \pm 0.0123)$.
Whole model

Table 10: Summary of fit

\begin{tabular}{ll}
\hline $\mathrm{R}^{2}$ & \\
$\mathrm{R}^{2}$ Adj & 12.54209 \\
Root mean square error & 44.9125 \\
Mean of response & 8 \\
Observations (or sum wgts.) & \\
\hline
\end{tabular}

Table 11: Analysis of variance

\begin{tabular}{lllll}
\hline Source & DF & Sum of squares & Mean square & F ratio \\
\hline Model & 3 & 15540.104 & 5180.03 & 32.9301 \\
Error & 5 & 786.521 & 157.30 & $\mathrm{p}>\mathrm{F}$ \\
C. Total & 8 & 16326.625 & & $0.0010^{*}$ \\
\hline
\end{tabular}

Table 12: Parameter estimates

\begin{tabular}{lllll}
\hline Term & Estimate & Standard error & t ratio & $\mathbf{p}>|\mathbf{t}|$ \\
\hline HPMC 5 (mg) & 0.0547918 & 0.027173 & 2.02 & 0.0998 \\
Glycerol (ml) & 51.451837 & 27.1729 & 1.89 & 0.1168 \\
SSG (mg) & 0.2541837 & 0.552248 & 0.46 & 0.6646 \\
\hline
\end{tabular}

HPMC: Hydroxypropyl methylcellulose, SSG: Sodium starch glycolate

Table 13: Summary of fit

\begin{tabular}{ll}
\hline $\mathrm{R}^{2}$ & 0.147204 \\
$\mathrm{R}^{2}$ Adj & -0.49239 \\
Root mean square error & 6.357258 \\
Mean of response & 44.9125 \\
Observations (or sum wgts.) & 8 \\
\hline
\end{tabular}

Table 14: Analysis of variance

\begin{tabular}{lllll}
\hline Source & DF & Sum of squares & Mean square & F ratio \\
\hline Model & 3 & 27.90445 & 9.3015 & 0.2302 \\
Error & 4 & 161.65890 & 40.4147 & $\mathrm{p}>\mathrm{F}$ \\
C. Total & 7 & 189.56335 & & 0.8713 \\
\hline
\end{tabular}

Table 15: Parameter estimates

\begin{tabular}{lllll}
\hline Term & Estimate & Standard error & t ratio & $\mathbf{p}>|\mathbf{t}|$ \\
\hline Intercept & 41.243333 & 10.48894 & 3.93 & $0.0171^{*}$ \\
HPMC 5 (mg) & 0.00934 & 0.017981 & 0.52 & 0.6309 \\
Glycerol (ml) & 6 & 17.98104 & 0.33 & 0.7554 \\
SSG (mg) & -0.166667 & 0.299684 & -0.56 & 0.6078 \\
\hline
\end{tabular}

HPMC: Hydroxypropyl methylcellulose, SSG: Sodium starch glycolate

Thickness of the formulations was found to be lowest for F2 (65.66 $\mu \mathrm{m} \pm 2.08)$ and highest for $\mathrm{F} 4(95 \mu \mathrm{m} \pm 2)$. Folding endurance for film formulation was found to be lowest for F6 $(83 \pm 2.160)$ and highest 
Table 16: Results of the optimized formula

\begin{tabular}{|c|c|c|c|c|c|}
\hline $\begin{array}{l}\text { Drug content }(\%) \pm S D \\
(n=3)\end{array}$ & $\begin{array}{l}\text { Thickness }(\mu \mathrm{m}) \pm S D \\
(n=3)\end{array}$ & $\begin{array}{l}\text { Surface } p H \pm S D \\
(n=3)\end{array}$ & $\begin{array}{l}\text { Folding endurance } \pm S D \\
(n=3)\end{array}$ & $\begin{array}{l}\text { Disintegration time (s) } \\
\text { Predicted }\end{array}$ & $\begin{array}{l}\text { Disintegration time (s) } \\
\text { Actual } \pm \operatorname{SD}(n=3)\end{array}$ \\
\hline $97.13 \pm 0.0044$ & $90 \pm 1.632$ & $7.46 \pm 0.133$ & $103 \pm 6.23$ & 42.86 & $43 \pm 1.632$ \\
\hline
\end{tabular}

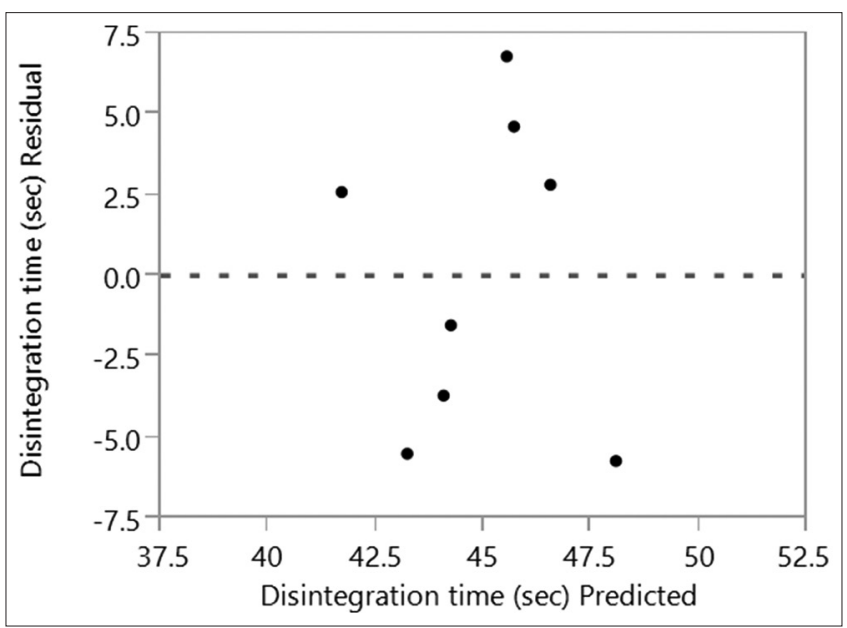

Fig. 8: Residual by predicted plot

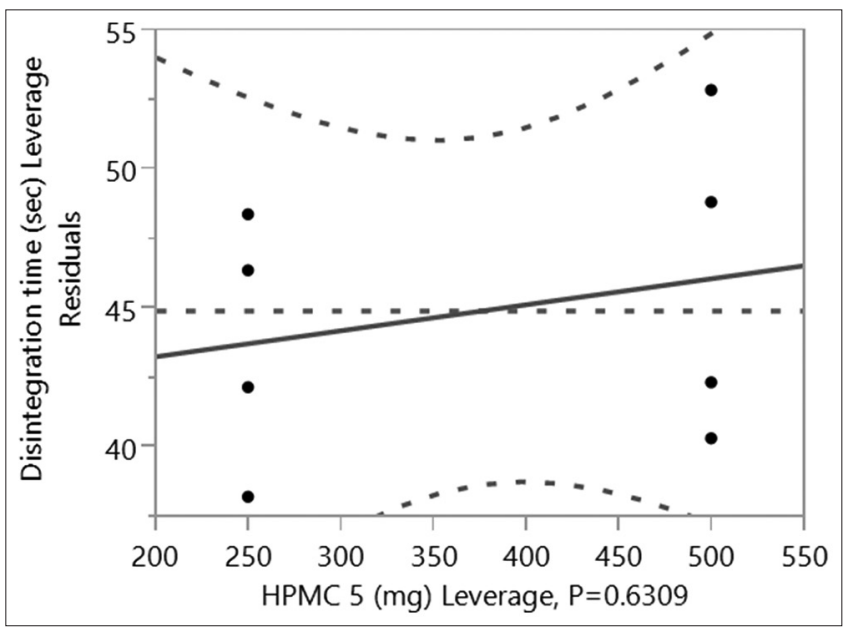

Fig. 9: Hydroxypropyl methylcellulose 5 (mg) leverage plot

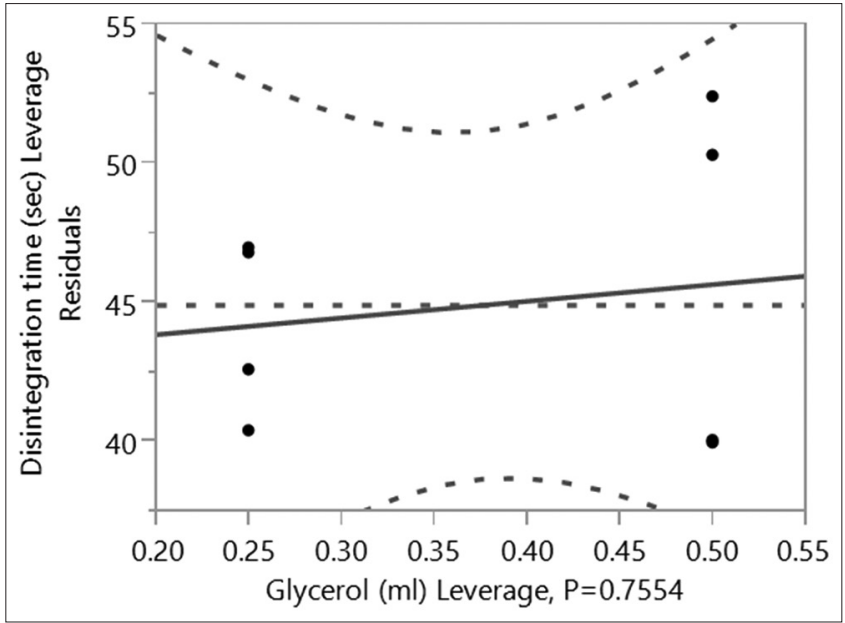

Fig. 10: Glycerol (ml) leverage plot

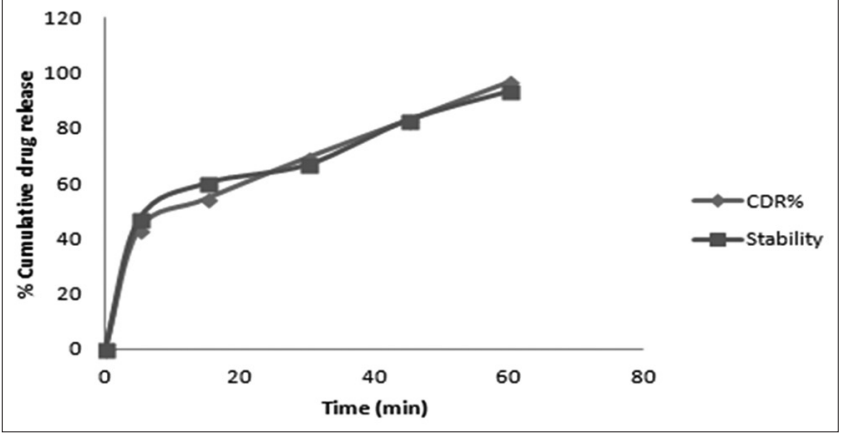

Fig. 11: In vitro release profile of the optimized formula before and after short-term accelerated stability study

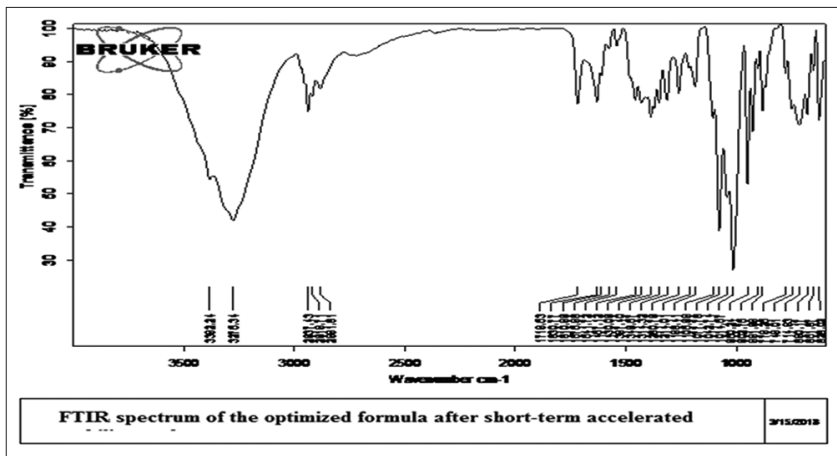

Fig. 12: Fourier transform-infrared spectrum of the optimized formula after short-term accelerated stability study

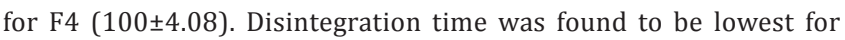
F4 (37.66 $\pm 2 \mathrm{~s})$ and highest for F8 (52 $\pm 2 \mathrm{~s})$. Surface $\mathrm{pH}$ was found to be lowest for F1 $(7.07 \pm 0.0309)$ and highest for F4 $(7.466 \pm 0.36)$. Percentage CDR of screening batches was found to be lowest for F1 (46.04\% \pm 0.00124$)$ and highest for F4 $(96.12 \% \pm 0.00124)$. Drug content for optimized formulation was found to be $97.13 \% \pm 0.0044$. Percentage CDR was found to be $96.89 \% \pm 0.0033$ may be due to rapid uptake of water, followed by rapid and enormous swelling of SSG. Thickness of film formulation was found to be $90 \mu \mathrm{m} \pm 1.639$ and folding endurance was found to be $103.33 \pm 6.23$. Surface $\mathrm{pH}$ of film formulation was found to be $7.46 \pm 0.133$ and disintegration time of films formulation was found to be $43 \pm 1.6329$ s (predicted: $42.8 \mathrm{~s}$ ). Thus, the actual value of the disintegration time was in close agreement with the predicted value. Post short-term accelerated stability studies showed that ACV remained stable as evident by the peaks shown in the FTIR (Fig. 5); also, the percentage CDR was recorded at $93.36 \%$ which was close to the original value of $96.12 \%$.

\section{CONCLUSION}

As the solubility profile of ACV-SD showed an improvement, it was concluded that such ACV-SD could be beneficial in enhancement of dissolution and consequently the oral bioavailability of ACV. The optimized oral films of ACV-SD were rapidly disintegrating indicating the success of this research work. Future scope of the study would be to study its effectiveness and safety in animals and humans followed by scale-up. 


\section{ACKNOWLEDGMENT}

The authors would like to acknowledge the support of the management and Principal of Krupanidhi College of Pharmacy, Bangalore.

\section{AUTHOR'S CONTRIBUTION}

Both the authors have equally contributed toward the research and research article.

\section{CONFLICTS OF INTEREST}

The authors declare that they have no conflicts of interest.

\section{REFERENCES}

1. Thin Film Drug Manufacturing Market to be Worth US\$15,984.3 Billion by 2024: Improved Therapeutic Output Encourages Healthcare Industry to Adopt Thin Film Drugs; 2017. Available form: https://www. prnewswire.com/news-releases/thin-film-drug-manufacturing-marketto-be-worth-us 159843-billion-by-2024-improved-therapeutic-outputencourages-healthcare-industry-to-adopt-thin-film-drugs-625478933. html. [Last accessed on 2018 Apr23].
2. Irfan M, Rabel S, Bukhtar Q, Qadir MI, Jabeen F, Khan A. Orally disintegrating films: A modern expansion in drug delivery system. Saudi Pharm J 2016;24:537-46.

3. Yassin GE, Abass HA. Design and evaluation of fast dissolving oro-dispersible films of metoclopramide hydrochloride using $3^{2}$ multifactorial designs. Int J Pharm Pharm Sci 2016;8:218-22.

4. Prakasam K, Bukka R. Evaluation of cellulose polymers for buccal film formulation of rasagiline. Int J Pharm Pharm Sci 2014;7:83-7.

5. Acyclovir-Drug Bank; 2017. Available from: https://www.pubchem. ncbi.nlm.nih.gov/compound/acyclovir\#section=Top. [Last cited on 2005 June 13]

6. Xu JW, Xie HJ, Cao QR, Shi LL, Cao Y, Xu XY, et al. Enhanced dissolution and oral bioavailability of valsartan solid dispersions prepared by a freeze-drying technique using hydrophilic polymers. Drug Deliv 2016;23:41-8.

7. Baka E, Comer JE, Novak KT. Study of equilibrium solubility measurement by saturation shake-flask method using hydrochlorothiazide as model compound. J Pharm Biomed Anal 2008;46:335-41.

8. Nokhodchi A, Talari R, Valizadeh H, Jalali MB. An investigation on the solid dispersions of chlordiazepoxide. Int J Biomed Sci 2007;3:211-6. 